\title{
A VOZ DOS TRABALHADORES SOBRE A GESTÃO PARTICIPATIVA EM UM HOSPITAL DE GRANDE PORTE
}

\author{
Maria Teresa da Costa Freire \\ Psicóloga - Mestra em Saúde Coletiva /Secretaria de Estado da Saúde Pública do Rio \\ Grande do Norte. E-mail: teresaf@uol.com.br \\ Maísa Paulino Rodrigues
}

Cirurgiã-Dentista - Doutora em Ciências da Saúde /Professora do Depto de Odontologia da UFRN/ Docente do Programa de Pós-graduação em Saúde Coletiva/UFRN.

E-mail: maisarodrigues@ufrnet.br

Geórgia Sibele Nogueira da Silva

Psicóloga - Doutora em Medicina Preventiva- FMUSP/ Professora do Depto de Psicologia da UFRN. Docente do Programa de Pós-graduação em Psicologia/UFRN.

E-mail: gsibele@uol.com.br

\section{Ricardo Henrique Vieira de Melo}

Cirurgião-Dentista - Mestre em Saúde da Família/ Secretaria Municipal de Saúde de Natal.

E-mail: ricardohvm@gmail.com

Rosana Lúcia Alves de Vilar

Enfermeira - Professora do Departamento de Enfermagem da UFRN/Docente do Programa de Pós-graduação em Saúde da Família-RENASF/UFRN.

E-mail: rosanaalvesrn@gmail.com

\section{RESUMO}

Este estudo relata a percepção dos trabalhadores de um hospital de grande porte, localizado na cidade de Natal/RN, acerca do processo de gestão participativa implantado após a adoção de arranjos e dispositivos institucionais propostos pela Política Nacional de Humanização. Trata-se de um Estudo de Caso realizado em 2012, com 24 trabalhadores que vivenciaram o cotidiano desse serviço. Utilizou-se a pesquisa documental e entrevistas semiestruturadas. O material transcrito foi submetido ao software Alceste, produzindo uma análise lexicográfica. Identificaram-se os núcleos de sentidos e os significados expressos nas falas, usando-se como suporte a análise de conteúdo proposta por Bardin (2010). Apreenderam-se as categorias percepção sobre gestão participativa; mudanças percebidas com a gestão participativa e percepção das dificuldades e desafios da gestão participativa. Os resultados mostraram corresponsabilização dos profissionais com a gestão; melhorias no processo de trabalho; efetivação da Política de Educação Permanente; melhoria dos indicadores hospitalares; criação de Unidades Funcionais, refletindo na humanização das ações; constituição de colegiados gestores e criação de ouvidoria. As dificuldades relacionam-se ao pouco apoio da gestão estadual e a fragmentação da rede de serviços de saúde. Concluiu-se que houve avanços e produtos efetivos, entretanto, faz-se necessário fomentar e intensificar a participação de usuários e trabalhadores respectivamente.

PALAVRAS-CHAVE: gestão participativa; humanização da assistência; assistência hospitalar; percepção de trabalhadores. 


\title{
WORKERS' VOICE REGARDING PARTICIPATORY MANAGEMENT IN A LARGE HOSPITAL
}

\begin{abstract}
This study reports the perception of workers of a large hospital located in the city of Natal, State of Rio Grande do Norte, Brazil, about the participatory management process deployed after the adoption of measures and institutional arrangements proposed by the National Humanization Policy. This is a case study conducted in 2012 with 24 workers who experienced the daily life of this service. A documentary research and semi-structured interviews were performed. The transcribed material was submitted to the Alceste ${ }^{\circledR}$ software in order to carry out a lexicographical analysis. The nuclei of senses and the meanings expressed in the discourses were identified using as support the content analysis method proposed by Bardin (2010). The emerging categories were: perception about participatory management; changes perceived in participatory management; and perception of the difficulties and challenges of participatory management. The results showed professionals' joint responsibility towards management; improvement of the work process; completion of the Continuing Education Policy; improvement of hospital indicators; creation of Functional Units reflecting on humanization of actions; establishment of collegiate management; and creation of an ombudsman channel. The difficulties relate to the little support provided by the state management and the fragmentation of the health services network. It was concluded that there was progress and effective products; however, it is necessary to encourage and intensify the participation of users and workers respectively.
\end{abstract}

KEYWORDS: participatory management; health care humanization; hospital health care; workers' perception.

\section{A VOZ DOS TRABALHADORES SOBRE A GESTÃO PARTICIPATIVA EM UM HOSPITAL DE GRANDE PORTE}

\section{INTRODUÇÃO}

A gestão é um campo da vida humana que envolve as práticas de lidar com conflitos nas organizações, os quais emergem por não haver previamente coincidência entre as finalidades da organização e os interesses e desejos dos seus participantes - no caso das organizações que prestam serviços de saúde: entre gestores e trabalhadores. O desafio de lidar com processos de trabalho e pessoas que os realizam e de pensar a gestão em saúde no SUS impõe ainda o diálogo com as políticas públicas (BARROS; BARROS, 2007).

A proposta da cogestão consiste em incluir os sujeitos nos processos de gestão de uma organização, modificando o lugar institucional do gestor e alterando o modo de inscrição da função de gestão. A inclusão do trabalhador nos processos de gestão de uma organização de saúde pretende funcionar como dispositivo para a dissolução da separação entre quem formula/gere de quem executa o trabalho como tarefa predeterminada. É essa separação que permite a expropriação da dimensão de produção de vida (de si e do mundo) 
do trabalho e a submissão dos objetos de investimento do trabalhador aos interesses do gestor/organização (OLIVEIRA, 2012).

A cogestão pressupõe, desse modo, arranjos concretos que se constituam em espaços de negociação, de trabalho e de gestão entre sujeitos com sentido mais coletivo. Nessa perspectiva, a Política Nacional de Humanização (PNH) elucida que uma gestão compartilhada, portanto mais democrática, nos serviços de saúde, no cotidiano das práticas de saúde, que envolvem as relações, os encontros entre usuários, sua família e rede social com trabalhadores e equipes de saúde, precisa de alterações nos modos de organização do trabalho em saúde. Ou seja, que se alterem os processos de definição das tarefas, responsabilidades e encargos assumidos pelos trabalhadores. Nessa perspectiva, a cogestão expressa, ao mesmo tempo, inclusão de novos sujeitos nos processos decisórios e alteração das tarefas da gestão, que incorpora também função de análise institucional, de contextos e da política, função de formulação, portanto de exercício crítico-criativo e função pedagógica (BRASIL, 2012).

O exercício da gestão ampliada e compartilhada para a produção de mudanças nas organizações de saúde requer vontade política, provisão de condições concretas e método, sem o qual se corre o risco de se transformar a cogestão apenas em um exercício discursivo.

É nessa perspectiva que a própria gestão se apresenta como um método, pois ela tanto pode se prestar ao exercício do controle dos sujeitos, como pode ser um importante espaço de reinvenção do trabalho, produzindo sentido desde pressupostos éticos - como, por exemplo, a base doutrinária do SUS (equidade, universalidade, integralidade e participação cidadã). Reinventar as organizações pressupõe alterar o modo de produção e os fluxos de poder. Em geral, as organizações de saúde (que são realidades hipercomplexas) têm uma disposição centralizadora do poder, fomentando processos de comunicação pouco transversais e colocando em relação apenas os iguais. Em outras palavras: o exercício da comunicação se dá entre os pares (chefes com chefes, médicos com médicos, enfermeiros com enfermeiros, e assim por diante), dificultando a emergência de processos instituintes (BRASIL, 2012).

Para mudar essa forma de fazer é necessário adotar uma nova arquitetura que permita a ampliação da superfície de contato entre as pessoas, possibilitando o encontro das diferenças. Essa orientação se sustenta pelo argumento de que os objetos com que os trabalhadores lidam são complexos (risco de adoecer e da doença), exigindo ações interdisciplinares. Para que a ação interdisciplinar aconteça, é imprescindível que haja organização de espaços para o encontro e composição das diferenças, para arranjar formas de intervenção que articulem os diferentes territórios de saberes e práticas.

Com base nesses pressupostos, o Hospital Giselda Trigueiro (HGT) aderiu à PNH e implantou o dispositivo da cogestão, desde o ano de 2007, tentando envolver trabalhadores e usuários nessa construção. Contudo, apesar desse processo de construção democrática, os significados de uma política de saúde provocam interpretações diversas desde o seu nascedouro, e as atribuições de sentido dirigidas a elas nem sempre vão coincidir com seus reais propósitos. Essas interpretações, por sua vez, se ancoram num conjunto de habitus entendido como um conhecimento adquirido, um haver, um capital que indica uma apropriação - que serve de referência para a representação dos agentes envolvidos na implantação da cogestão (BOURDIER, 1998; 2002). Assim, ouvir as várias vozes e 
discursos que circulam em torno do "fazer ver e fazer crer" (BOURDIER, 1998) é imprescindível para os rumos da construção dessa experiência. A partir dessa perspectiva o presente artigo analisa os sentidos atribuídos à cogestão por parte dos sujeitos diretamente implicados na implantação dessa política no HGT no Rio Grande do Norte, percorrendo o itinerário do processo de construção da gestão participativa, e analisando as vozes dos implicados em tal processo por meio do estudo dissertativo realizado.

\section{CONTEXTUALIZANDO O HOSPITAL GISELDA TRIGUEIRO E O OLHAR PARA A COGESTÃO}

O Hospital Giselda Trigueiro, lócus desta pesquisa, é um hospital de grande porte, referência para urgências e emergências em doenças infecciosas, localizado na região oeste da cidade do Natal, capital do Rio Grande do Norte. É uma instituição pública que integra a rede hospitalar da Secretaria de Estado da Saúde Pública do Rio Grande do Norte (SESAP). Oferece assistência exclusiva ao usuário SUS. Constitui-se como um campo de ensino e pesquisa e alberga o Departamento de Infectologia da Universidade Federal do Rio Grande do Norte (UFRN), oferecendo residência médica em infectologia. É, também, campo de estágio para várias instituições voltadas à formação profissional em saúde de diferentes categorias profissionais, nos níveis técnicos, de graduação e pós-graduação (SESAP/RN).

O HGT dispõe de serviços de internação hospitalar, hospital-dia e ambulatórios que ofertam atendimento para Hanseníase, Tuberculose, Doenças Sexualmente Transmissíveis, Síndrome da Imunodeficiência Adquirida (AIDS), Esquistossomose, Doença de Chagas, Hepatites virais e Leishmaniose. Possui 126 leitos para internação, que correspondem a 27 leitos para infectologia em geral, 20 leitos para AIDS, 29 leitos para tuberculose e pneumologia, 26 leitos em infectologia pediátrica, 07 leitos na UTI, e 16 leitos de observação no pronto-socorro. O Sistema de Assistência Domiciliar (SAD) do HGT acompanha 30 usuários, e o hospital-dia oferece 05 leitos diários. Além disso, o HGT realiza atendimentos de urgência e emergência em infectologia por 24horas, totalizado uma média de 3.300 atendimentos e 220 internações mensais. No ambulatório de programa para Hanseníase, DST\AIDS, Leishmaniose e acidentes biológicos, realizam-se 1.300 atendimentos mensais. O hospital oferece ainda os serviços de Informações Toxicológicas (IT) e do Centro de Referência em Imunobiológicos Especiais (CRIE).

A exemplo da realidade de diversos hospitais brasileiros, a história do HGT foi marcada pela fragmentação dos processos de trabalho, insuficiência de recursos humanos, desvalorização dos trabalhadores e de gestões pouco qualificadas. Esses fatores repercutiam no cotidiano do trabalho, gerando adoecimento, desmotivação e absenteísmo. Somava-se a isso a verticalização na tomada de decisões e a ausência de espaços democráticos que permitissem a troca de experiência e interlocução entre os sujeitos.

É sabido que modelos de administração verticalizados têm contribuído para a centralização do poder e o estabelecimento de relações autoritárias, determinando a escassez de vínculos entre trabalhadores e usuários, pouca responsabilização e queda na qualidade da atenção à saúde. Avançar na direção da integralidade do cuidado e da resolubilidade dos problemas de saúde requer envolver os "sujeitos da saúde", através da participação, por meio de formulação da política e da socialização do poder de decisão, fazendo-se necessário um 
redirecionamento do processo de trabalho, visando executar o planejamento, a organização e a avaliação das ações de saúde (BENEVIDES; PASSOS, 2005). Para pensar a gestão de um hospital é preciso redimensionar as relações de saber, poder e afetos que traspassam as tecnologias biomédicas e relacionais no cotidiano.

A noção de desenho tecno-assistencial deixa mais claro que o modelo é uma configuração provisória de práticas, que representa sempre confronto entre conservação e mudança. Conviver com a mudança permite viver em realidades em construção, promovendo as possibilidades e as escolhas coletivas. Nessa linha de pensamento Luiz Cecílio (1997) propõe desprezar a "segurança" que a ideia de "modelo" possa trazer e convida os sujeitos a assumirem uma postura mais criativa e "arriscada" de modelar os serviços, tomando como referência as necessidades dos usuários. A possibilidade de elaborar novas combinações entre os diferentes recursos disponíveis e sua relação com o uso social de cada arranjo tecnológico e assistencial se constitui sempre no ofício de desenhar estratégias tecno-assistenciais. Essa noção de desenho permite acenar com os campos de possibilidades como estratégia de gestão e compreender que nenhum método pode ser considerado perfeito.

Seguindo esses preceitos e tomando por base as diretrizes e os dispositivos da Política Nacional de Humanização, o HGT, deu início, em 2007, a um novo desenho de gestão, envolvendo trabalhadores, usuários e gestores, para que juntos tentassem modificar as práticas predominantes na instituição, isto é, deflagrando o processo de gestão participativa.

A ideia da construção de uma gestão democrática e participativa teve origem há seis anos, quando um grupo de profissionais médicos do HGT solicitou ao secretário estadual de saúde, à época, que acatasse a indicação de um nome pertencente ao corpo clínico do hospital para o cargo de Direção Geral do HGT. A solicitação foi atendida e uma médica do Pronto-Socorro foi nomeada, assumindo além da sua função de plantonista, o desejo e a disposição de consolidar uma nova forma de gestão e atenção à saúde como foco na Gestão Participativa (SILVA; FÉ; MARTINS, 2009). Deu-se início então a um trabalho coletivo, processual e desafiador, com o objetivo de ofertar uma atenção à saúde mais humanizada, com vistas à integralidade do cuidado. Nesse contexto, iniciaram-se as mudanças no processo de gestão, por meio da valorização e estímulo à participação dos trabalhadores e usuários no tocante ao planejamento e à avaliação das ações, fomentando o estímulo à corresponsabilização pelos rumos do hospital e da saúde pública, subsidiados pela Política Nacional de Humanização.

É oportuno destacar que a PNH desabrocha no ano de 2003, com o objetivo de deflagrar um movimento ético, político e institucional visando enfrentar e superar os modos de gestão e de cuidado incoerentes com o direito inalienável à saúde, reafirmando a garantia do acesso universal e equitativo às ações integrais de saúde. Tal política emerge dos acúmulos do SUS, navegando no reconhecimento dos avanços alcançados e na análise dos seus paradoxos e desafios, a partir de sua própria experimentação como política pública e prática social (PASCHE, 2009).

Essa Política tem sido construída seguindo princípios metodológicos, sabidamente inclusivos, como o Método da Tríplice Inclusão: inclusão dos sujeitos, dos coletivos e da perturbação que essas inclusões produzem nos modos de gerir os serviços de saúde e nas relações clínicas. Assim, o contato com a diferença vai exigir que as instituições passem a 
lidar com os conflitos, e não a evitá-los; aliás, as organizações e seu processo de gestão ampliado passam a produzir perturbações, pois o encontro entre as diferenças propicia a emergência de tensões advindas da relação entre sujeitos que portam diferentes desejos, interesses e necessidades (BRASIL, 2010).

Assim, a reorganização dos espaços deve produzir Unidades de Produção (UP), onde equipes de referência se constituiriam para lidar com seus objetos complexos. Essas unidades de produção e equipes de referência são conceitos e ferramentas basilares para a reorganização das práticas de gestão e de saúde porque, a partir do estabelecimento de contratos internos (nas equipes e nas organizações a que pertencem), se estabelecem acordos com outras equipes e serviços - fundando, assim, possibilidades concretas de reorganizar a rede de atenção à saúde, sem a qual não se garante o cuidado longitudinal. A produção de contratos entre equipes e serviços é uma das funções da gestão, tarefa sem a qual não se ampliam as estratégias de corresponsabilização (BRASIL, 2012).

Apostar nas mudanças dos modelos de atenção e de gestão é instituir novos arranjos institucionais e dispositivos para dentro dos serviços, ressignificando o trabalho em saúde. Essa é uma aposta onde gestão e atenção são consideradas indissociáveis e onde o conceito de resultado em saúde também é ampliado: produzir saúde e produzir sujeitos com maior capacidade de análise e de intervenção diante do cotidiano (BRASIL, 2012).

Portanto, para implantar o novo desenho de atenção e gestão, tomaram-se como base as diretrizes da PNH, o aporte teórico existente, e visitas técnicas a hospitais que apresentavam experiências bem-sucedidas na temática em foco.

\section{A IMPLANTAÇÃO DA COGESTÃO NO HGT: O PROCESSO}

Inicialmente, em 2007, foi realizado um diagnóstico institucional que revelou os vários problemas do HGT. Dentre muitos, apontaram-se problemas de superlotação no hospital, de subfinanciamento do setor, de práticas de trabalho mecanizadas, o histórico de gestões autoritárias, os conflitos interpessoais, a pouca valorização dos trabalhadores e o desestímulo dos profissionais. Todos os problemas elencados determinavam a baixa qualidade dos serviços e, consequentemente, a insatisfação dos trabalhadores e gestores do hospital.

Partindo desse cenário foram planejadas as estratégias que se seguem:

-Reuniões para sensibilização envolvendo profissionais, gerentes, usuários e demais colaboradores das equipes de trabalho, para apresentar o diagnóstico institucional e a proposta de mudança de gestão, objetivando um maior envolvimento e adesão dos mesmos e integração do grupo;

-Seminários, oficinas e rodas de conversa, dirigidos às equipes da assistência, dos setores específicos e as gerências, envolvendo temas do cotidiano profissional e institucional;

- Constituição de apoio técnico: inclusão na equipe de uma consultora da PNH/Ministério da Saúde, de modo a contribuir para a efetivação da Gestão Participativa; 
-Constituição de parcerias intersetoriais, agregando representantes da rede de saúde, Núcleo de Estudos em Saúde Coletiva (NESC/UFRN) e segmentos organizados do controle social;

-Criação de um grupo interno de apoiadores, objetivando estruturar, acompanhar e avaliar a condução do processo. Inicialmente a instituição contou com uma apoiadora institucional, que desenvolvia junto aos demais colaboradores o acompanhamento da cogestão. A partir de 2012, ampliou-se o grupo de apoiadores institucionais, fortalecendo assim os mecanismos de avaliação interna, de formação e de apoio aos gerentes, trabalhadores e gestor do hospital;

- Capacitação técnica direcionada a todos os gerentes, profissionais, trabalhadores de diversas categorias e colaboradores da instituição;

-Dimensionamento das necessidades estruturais e de pessoal, por meio de levantamento do funcionamento das rotinas, fluxos de atendimentos, protocolos, comunicação institucional, entre outros;

-Reformulação do organograma institucional do HGT, e elaboração de um novo Regimento Interno, tendo como foco a cogestão e a reorganização dos serviços através da criação de Unidades Funcionais de Produção;

•Constituição de Colegiados nas Unidades Funcionais;

- Constituição de um Colegiado Gestor Ampliado para atuar como órgão consultivo, presidido pela Direção Geral, Direções Executivas, Gerentes das Unidades, representantes dos trabalhadores e de usuários;

- Implantação de novos dispositivos e arranjos voltados para a reorganização do processo de trabalho e qualificação da assistência: constituição de protocolos clínicos por enfermarias, estudos de casos clínicos e de temáticas voltadas para a valorização do trabalho e do trabalhador, planejamentos estratégicos com metas e ações, Política de Educação Permanente a partir da necessidade dos trabalhadores e setores, constituição de espaços coletivos voltados para a reflexão junto aos trabalhadores e usuários: Fórum dos trabalhadores, Fórum de Usuários, entre outros.

No momento seguinte foi deflagrado um amplo movimento de sensibilização e mobilização junto aos trabalhadores e usuários, com vistas a envolvê-los de forma expressiva no processo. Com a adesão desses atores, deu-se início a implantação da nova proposta de acordo com as etapas planejadas, que aconteceram, para algumas delas, de forma simultânea:

-Reuniões para sensibilização: foram efetivadas várias reuniões comtemplando os profissionais da UTI, as chefias médica e de enfermagem, a Comissão de Controle de Infecção Hospitalar, que debateram e acrescentaram sugestões ao projeto. Seguiu-se com a mesma metodologia junto aos trabalhadores e gerentes setoriais. $\mathrm{Na}$ oportunidade foi discutida a Política Nacional de Humanização, os conceitos de gestão participativa e as experiências exitosas implantadas em outros serviços. Eclodiu então, o interesse dos trabalhadores da UTI em acolher o novo modelo de gestão, ao mesmo tempo em que trabalhadores dos demais setores iam manifestando o interesse em conhecer o projeto. 
- Oficinas e rodas de conversa: objetivando sensibilizar os profissionais e gerentes de diversos setores, realizaram-se oficinas e rodas de conversa, importantes espaços de reflexão e debate acerca dos problemas cotidianos. Esse método contribuiu para estimular a participação dos trabalhadores e buscar transformações nos processos da atenção e da gestão em saúde.

-Seminário: foi realizado um "Seminário Temático sobre Gestão Participativa" em abril de 2008, envolvendo 110 profissionais do hospital, trabalhadores e gestores da rede estadual e municipal, consultores da PNH, docentes da UFRN e representantes do controle social. Pode-se dizer que foi o coroamento do Projeto.

- Constituição de apoio técnico: constitui-se uma equipe de apoiadores internos e de apoiadores externos, entre estes, profissionais e trabalhadores da instituição, docentes e profissionais do Departamento de Infectologia da UFRN, uma apoiadora institucional e uma consultora do Ministério da Saúde, que passou a acompanhar a implantação do Projeto, analisando o processo e os resultados.

- Constituição de parcerias intersetoriais: estabeleceu-se parceria institucional com a Secretaria Municipal de Saúde de Natal (SMS), com o NESC e com representantes do controle social, visando ao fortalecimento do novo desenho delineado.

- Capacitação em Gestão Participativa para Gestores e Trabalhadores: foram desenvolvidos 11 módulos, com estudos teórico/prático, abordando temas necessários à compreensão e construção de conhecimentos acerca da gestão participativa, com uso de metodologias ativas visando subsidiar e instrumentalizar os sujeitos para intervenções mais qualificadas. Ressalta-se que as capacitações, cursos e oficinas estavam alinhados aos os princípios e diretrizes da Política Nacional de Educação Permanente em Saúde (MATHIAS, 2010, p.12).

Nessa mesma direção, foi feita uma "Capacitação em Gestão Participativa para Gestores e Trabalhadores do HGT". A escolha dos temas foi gradualmente construída, de acordo com necessidades e dificuldades identificadas ao longo do processo de implantação da Gestão Participativa. A realização dessa capacitação compreendeu 11 módulos de oito horas/aula cada, realizados entre o período de junho de 2009 a setembro de 2011. Os módulos temáticos do curso se constituíram em: O desafio de uma Gestão Participativa na Rede; Organização e Gestão do Trabalho no Hospital; Organização dos processos de trabalho nas unidades; A construção das redes de atenção do SUS: Interrogando o hospital público nesse contexto; Planejamento e Gestão: Técnica e Trabalho; Planejamento na Cogestão Missão e prioridades das unidades de produção do HGT; Relações interpessoais no processo de cogestão do HGT; Consolidação dos planos de ação setoriais; Inclusão dos usuários na gestão participativa: ouvidoria; Avaliando o processo de gestão participativa do HGT; Atribuições dos gerentes na gestão participativa (FREIRE et al., 2011).

-Reelaboração do Organograma Institucional e do Regimento Interno: foi reelaborado um novo organograma institucional e o Regimento Interno, seguindo as novas diretrizes propostas: cogestão e criação de unidades funcionais que têm o papel de organizar as ações de saúde por atividades afins. 
-Constituição de Colegiados por Unidades: foram constituídos os colegiados gestores por unidades funcionais. Estes tiveram por missão, a partir de então, construir um plano de trabalho junto com os gerentes, trabalhadores e usuários do setor, a fim de programar mudanças no cotidiano do trabalho.

-Constituição do Colegiado Gestor Ampliado: foi formado em 2009, como órgão consultivo, um Colegiado Gestor Ampliado, composto pelo gestor da instituição, gerentes das unidades de produção, representantes dos segmentos de trabalhadores e usuários e os apoiadores do Projeto. Esse dispositivo, contou, desde a sua constituição, com a participação dos trabalhadores e gestor do hospital garantindo o assento de representantes de usuários e de representantes da UFRN.

-Reuniões intersetoriais: emergiu a prática de reuniões intersetoriais sistemáticas, caracterizando-se como espaços de construção de acordos e pactuações, baseadas na busca de consensos para a resolução de problemas, com elaboração de protocolos, definições de rotinas e fluxos de trabalho.

-Política de Educação Permanente: as atividades de Educação Permanente foram sendo incrementadas, paulatinamente, atendendo à demanda reprimida existente nos diversos setores e unidades funcionais. Essa estratégia passou a ser uma prioridade dentro do projeto do novo desenho de gestão, tendo sido contemplada no Plano Geral de Ação do HGT.

-Inclusão dos Usuários no Processo de Cogestão: a porta de entrada dos usuários no processo da Gestão Participativa ocorreu via Programas já existentes no Hospital e através das Unidades Funcionais instaladas.

- Implantação do Serviço de Ouvidoria: foi implantado em dezembro de 2012 o serviço de ouvidoria, visando atender às demandas dos usuários sendo um importante canal de comunicação e de participação, seja através de pesquisas de satisfação ou por meio de informações espontâneas.

-Acolhimento com Classificação de Risco (ACCR): foi implantado, após adequação na área física em 2007 e da capacitação de enfermeiros, criando-se protocolos de classificação própria, com base na situação/queixa. A sala do ACCR possui espaço acolhedor, privacidade durante o atendimento e possibilita a comunicação dos que aguardam na sala de espera.

A "Produção de Registros" implantada vem sendo avaliada como um importante produto da Gestão Participativa no HGT, uma vez que os dados são registrados, organizados e analisados, produzindo informações fundamentais para o acompanhamento e avaliação dos indicadores hospitalares. Nessa direção, as estatísticas hospitalares vêm revelando indicadores que instrumentalizam o processo de avaliação, incentivando a busca pela qualidade da gestão e da atenção em saúde.

Durante o ano de 2012 essa experiência foi objeto de estudo de uma dissertação de mestrado, cujo objetivo foi analisar a percepção dos profissionais acerca do processo de gestão participativa implantado no HGT, cujo desenho metodológico e resultados apresentam-se a seguir. 


\section{METODOLOGIA}

A pesquisa aprovada pelo Comitê de Ética em Pesquisa do Hospital Universitário Onofre Lopes (CEP/HUOL), sob o protocolo $\mathrm{n}^{\circ}$. 03436412.1.0000.5292, teve como referência metodológica a triangulação de métodos (DENZIN, 1973), articulando abordagens socioantropológicas e utilizando as técnicas de entrevista semiestruturada, observação baseada em princípios etnográficos e a análise documental.

Para a pesquisa documental lançou-se mão dos documentos oficiais como as atas das reuniões do colegiado gestor da instituição, reuniões dos colegiados das unidades de produção, artigos publicados sobre a proposta e experiência, como também os registros de dados produzidos no período para avaliar os indicadores e as possíveis mudanças efetivadas. Além disso, foram utilizados os documentos oficiais da Direção do hospital: os Relatórios Anuais de Gestão de 2009 a 2012.

As entrevistas foram dirigidas aos profissionais de saúde envolvidos diretamente na implantação da gestão participativa. Os usuários foram excluídos por considerar-se incipiente a participação destes no processo, além do exíguo tempo para a formulação de uma dissertação de mestrado. Foram entrevistados 24 trabalhadores: aqueles que participaram ativamente do processo e aqueles que não tiveram participação efetiva, contemplando as seguintes categorias: gestor, gerentes de unidades funcionais de produção, profissionais de nível técnico e médio e trabalhadores terceirizados.

O material transcrito gerou um corpus que foi submetido ao software Alceste, produzindo uma análise lexicográfica por meio do agrupamento das raízes semânticas, definindo-as em classes a partir das palavras do conjunto do texto. Esse software conjuga uma série de procedimentos estatísticos aplicados a bancos textuais, como entrevistas, obras literárias, artigos de jornais, entre outros. Tem como objetivo principal descobrir a informação essencial do texto (CAMARGO, 1998). Seguiu-se a descrição analítica, identificando-se os núcleos de sentidos e os significados expressos nas falas (BARDIN, 2010; FLICK, 2009).

Após essa etapa, estabeleceram-se os recortes para obtenção das categorias e das unidades de análise (BARDIN, 2010). Fez-se opção pelas unidades de contexto que são constituídas pelos segmentos mais largos do conteúdo, ou seja: são os temas maiores das entrevistas que foram decompostas em unidades de análise temática e posteriormente em temas semânticos mais simples. Seguiu-se com a decomposição dos discursos, a codificação dos temas e o agrupamento em categorias e subcategorias tomando por base a frequência das unidades de análise temática de ocorrência, visualizadas na Figura 1.

\begin{tabular}{|c|c|c|}
\hline CATEGORIAS & SUBCATEGORIAS & UNIDADES DE ANÁLISE \\
\hline \multirow{4}{*}{$\begin{array}{c}\text { PERCEPÇÃO SOBRE A } \\
\text { COGESTÃO }\end{array}$} & Participação & 14 \\
\cline { 2 - 3 } & Responsabilização & 37 \\
\cline { 2 - 3 } & Ter direito de voz & 14 \\
\cline { 2 - 3 } & Atendimento humanizado & 13 \\
\hline MUDANÇAS & Organização do processo & 32 \\
EFETIVADAS COM A & de trabalho & 38 \\
\cline { 2 - 3 } $\begin{array}{c}\text { IMPLANTAÇÃO DA } \\
\text { COGESTÃO }\end{array}$ & Gestão descentralizada & 10 \\
\cline { 2 - 3 } & Atenção ao usuário & \\
\hline
\end{tabular}




\begin{tabular}{|c|c|c|}
\hline & $\begin{array}{c}\text { Valorização do trabalho e } \\
\text { do trabalhador }\end{array}$ & 14 \\
\hline & $\begin{array}{c}\text { Descrença com a gestão } \\
\text { participativa }\end{array}$ & 43 \\
\cline { 2 - 3 } $\begin{array}{c}\text { DIFICULDADES PARA } \\
\text { EFETIVAÇÃO DA } \\
\text { COGESTÃO }\end{array}$ & $\begin{array}{c}\text { Desestruturação do sistema } \\
\text { de saúde no RN }\end{array}$ & 12 \\
\cline { 2 - 3 } & $\begin{array}{c}\text { Desvalorização do } \\
\text { trabalhador }\end{array}$ & 14 \\
\hline
\end{tabular}

Figura 01 - Distribuição das categorias e subcategorias simbólicas da cogestão.

\section{RESULTADOS E DISCUSSÃO}

\section{A percepção sobre a cogestão}

\section{PERCEPÇÃO SOBRE A COGESTÃO}

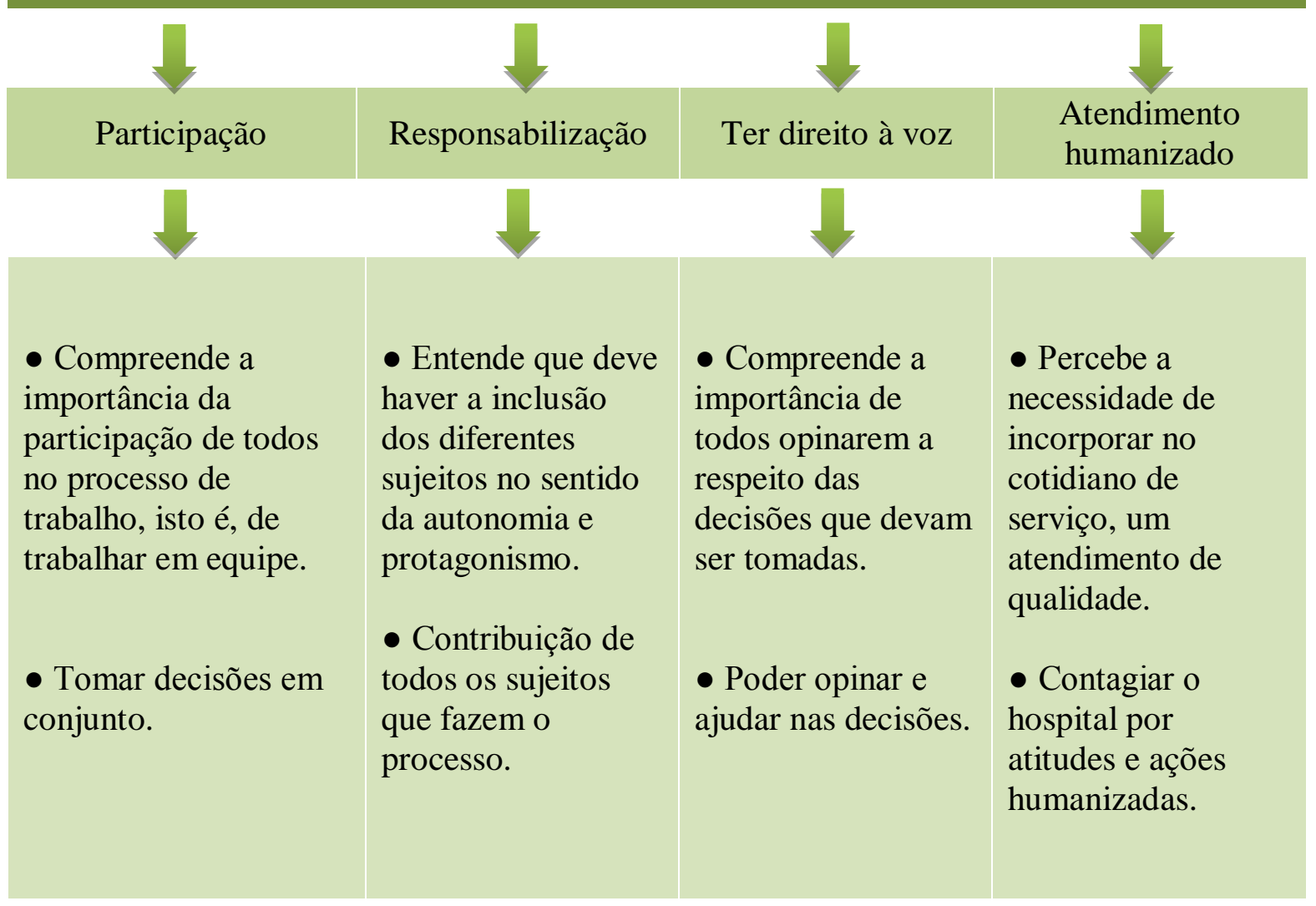

\section{Figura 02 - Percepção sobre a cogestão.}

Os profissionais do HGT percebem a cogestão como um movimento inovador e produtor de mudanças (Figura 2), e apresentam diversos significados para o termo: um espaço de construção de consensos e de parceiras; um espaço de compartilhamento das práticas que incidem sobre a melhoria da assistência; instituição de uma gestão participativa, onde os trabalhadores são sujeitos do processo, é o que expressam as falas colhidas durante as entrevistas.

“A gestão participativa é aquela que a gente pode opinar e podemos contribuir para o desenvolvimento da unidade em que trabalhamos. 
Você deixa de esperar que o gestor faça tudo e passa a administrar também com um conjunto de pessoas" (Enfermeiro).

"É uma divisão das responsabilidades que foi compreendida através do processo de capacitação e atualização dos conhecimentos. Essa gestão mexe muito com todos os profissionais envolvidos em cada unidade, e isso é gratificante, a gente passa a compreender o que é isto" (Gerente de setor).

O discurso dos sujeitos revela a compreensão que têm desse novo processo, e que se consolida ao estabelecer mecanismos concretos geradores de autonomia, os quais oportunizam seu protagonismo. Esse é um movimento que aposta em mudanças na micro e na macropolítica com foco na descentralização da tomada de decisões. Nesse contexto, é imprescindível a percepção e o desejo de mudanças por parte dos profissionais. As falas também descrevem o entusiasmo quando retratam a possibilidade de construir saídas e rotinas com o coletivo/ equipe de trabalho. Há tempos, os profissionais e trabalhadores de saúde buscam autonomia e condições reais de trabalho, a fim de poderem exercer de forma mais integrada e colegiada a produção da saúde.

Para a Política Nacional de Humanização, a inclusão de novos sujeitos nos processos decisórios das organizações de saúde, como prática de gestão, requer o estabelecimento de condições políticas e institucionais efetivas. Essas condições tomam expressão na forma de arranjos e dispositivos, os quais criam um sistema de cogestão, viabilizando a constituição de espaço-tempo para o exercício da gestão compartilhada, cogestão, co-governo (BRASIL, 2009b).

A inclusão de novos sujeitos nos processos de gestão traz como efeito a ampliação do "ser/fazer parte", da corresponsabilização, da produção do cuidado, uma vez que as definições, na forma de produção das ações de saúde, são coletivas, ou seja, derivadas de pactos entre os sujeitos, e não de imposições sobre eles (BRASIL, 2009b).

\section{Percepções sobre as mudanças}

\section{MUDANÇAS EFETIVADAS COM A IMPLANTAÇÃO DA COGESTÃO}
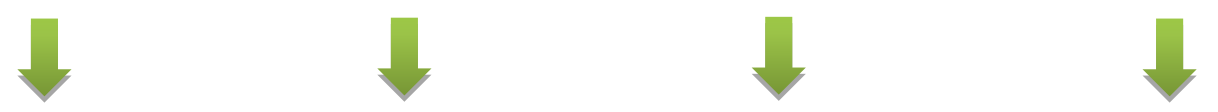

\begin{tabular}{|c|c|c|c|}
\hline Organização & $\begin{array}{c}\text { Gestão } \\
\text { descentralizada }\end{array}$ & Atenção ao usuário & $\begin{array}{c}\text { Valorização do } \\
\text { trabalho e do } \\
\text { trabalhador }\end{array}$ \\
\hline $\begin{array}{l}\text { - Percebem } \\
\text { mudanças efetivas } \\
\text { no processo de } \\
\text { trabalho e na } \\
\text { organização dos }\end{array}$ & $\begin{array}{l}\text { - Compreendem a } \\
\text { importância da } \\
\text { integração entre os } \\
\text { sujeitos, a } \\
\text { descentralização }\end{array}$ & $\begin{array}{l}\text { - Entendem que a } \\
\text { melhoria da } \\
\text { ambiência e a } \\
\text { organização dos } \\
\text { setores contribuem }\end{array}$ & $\begin{array}{l}\text { - Compreendem, } \\
\text { por meio da } \\
\text { implantação da } \\
\text { política de } \\
\text { educação }\end{array}$ \\
\hline
\end{tabular}




\begin{tabular}{|c|c|c|c|}
\hline $\begin{array}{l}\text { espaços. } \\
\text { - Apontam } \\
\text { mudanças nas } \\
\text { atitudes dos } \\
\text { trabalhadores e } \\
\text { gestores frente às } \\
\text { necessidades dos } \\
\text { setores. } \\
\text { - Percebem } \\
\text { mudanças na } \\
\text { comunicação entre } \\
\text { os setores e as } \\
\text { equipes de trabalho }\end{array}$ & $\begin{array}{l}\text { das decisões e da } \\
\text { implantação de } \\
\text { espaços que } \\
\text { possibilitaram a } \\
\text { inclusão de todos } \\
\text { no processo. } \\
\text { Todos podem } \\
\text { opinar }\end{array}$ & $\begin{array}{l}\text { para uma prática } \\
\text { mais acolhedora e } \\
\text { mais humanizada. }\end{array}$ & $\begin{array}{l}\text { permanente e } \\
\text { estruturação da } \\
\text { saúde ocupacional, } \\
\text { maior valorização } \\
\text { dos trabalhadores } \\
\text { percebem a gestão } \\
\text { mais próxima dos } \\
\text { trabalhadores. }\end{array}$ \\
\hline
\end{tabular}

\section{Figura 03 - Percepção sobre as mudanças}

Há, segundo os sujeitos entrevistados (Figura 3), vantagens na nova forma de gerir o cotidiano do trabalho no HGT. Destacam-se as mudanças na gestão e na produção do cuidado em saúde, sobretudo por meio da implantação do colegiado gestor ampliado, das unidades de produção e seus respectivos colegiados gestores. São mecanismos e arranjos que conduzem a ampliação de vínculos, de solidariedade e de corresponsabilização, mas que suscita também conflitos ou perturbações inerentes ao processo, contribuindo, portanto, para a construção de consensos em defesa do Hospital.

"Mudou a consciência do servidor. Mudaram os valores. Há transparência em cada setor, se sabe quem trabalha e o que faz. Antes ninguém era de ninguém. Agora se sabe desde a entrada, do acolhimento, as enfermarias, a possível alta do paciente, até o destino do óbito" (Gerente de setor).

"Mudou, agora todos nós conhecermos nossas atribuições, dentro do seu setor, dentro da instituição" (Técnico de enfermagem).

"O colegiado gestor ampliado é um espaço que vem amadurecendo como espaço democrático. O colegiado das unidades vem sendo um espaço aberto as falas... a voz" (Gerente Unidade de Produção).

Por meio da autonomia em seus processos de trabalho, observa-se o aumento da satisfação dos trabalhadores. Há um aumento de colaboração e de empatia entre os pares, refletidos nas relações interpessoais por meio da construção de parcerias, e de aumento de responsabilidades de forma consciente.

Para Cecílio (2000), à medida que a ideia de "gestão colegiada" vai sendo incorporada e transformada em parâmetro para se avaliar os processos de gestão, tem-se uma espécie de garantia de inovação da gestão, resultando em mudanças efetivas no paradigma clássico da 
administração pública, ou seja, cortando as mazelas da rigidez, do autoritarismo, da alienação dos trabalhadores, e da insensibilidade para com as necessidades dos usuários.

Nesse caminho, os sujeitos percebem os avanços do novo desenho institucional quando dizem haver abertura para o diálogo, sendo um processo construído sistematicamente no decorrer dos últimos anos, com trabalhadores, gestores e usuários, indicando uma nova forma de "fazer gestão", mais democrática, aberta e horizontal. Assim reafirmam que:

"A maior mudança é a implicação dos gerentes dentro do processo. Antigamente a gente não via isso. Tivemos mudanças, por exemplo, na participação do SAD (Serviço de Atendimento Domiciliar). Com essa nova gestão, a gente conseguiu envolver todas as pessoas no processo de organização da unidade. $\mathrm{O}$ motorista participa das reuniões efetivamente... e acha ótimo, emite opiniões sobre a logística dos transportes e isso é importante, incluir todos" (Gestor).

"Mudou muito. Há agilidade... fazemos funcionar. Mesmo sem os gerentes estarem presentes. Temos responsabilidade de fazer funcionar. Também há diálogo com a direção. Vejo muitos avanços. Se minha gerência não estiver, eu posso resolver, tenho autonomia" (Enfermeira).

"Hoje é mais compartilhado. Eu faço o serviço dela e ela faz o meu, se eu não estiver. Assim funciona no meu setor. O Hospital melhorou. Muitos percebem, e são conscientes das responsabilidades que têm" (Técnico administrativo).

Os espaços de troca são fundamentais, facilitam a escuta, as verbalizações, e apreensão dos ruídos, e também a circulação e debate a respeito dos conflitos. Assim, vai se evidenciando a integração e a motivação da equipe como parte de um todo que constrói a sua história coletivamente. Observa-se que no modelo anterior havia pouco interesse dos trabalhadores em participar das reuniões, e poucos eram os espaços destinados ao debate e à avaliação.

O modelo de gestão proposto pela PNH centra-se no trabalho em equipe, no planejamento horizontal e em espaços coletivos de compartilhamento do poder por meio de análises, decisões e avaliações pensadas e construídas socialmente. Dessa forma, os gestores orientam-se por metas compartilhadas com os colegiados de gestão (BRASIL, 2009a).

Nessa linha de compreensão há o reconhecimento por parte dos sujeitos da democratização das decisões no HGT à medida que referem existir:

"Ocorre conversa intersetorial, que não havia anteriormente, pois tudo era centralizado, tudo terminava junto à direção. A direção do HGT era sobrecarregada, não podia dar conta de todas as demandas. Agora é diferente, a conversa entre aos setores tem resolvido. Muitos profissionais fazem acordo diretamente com os profissionais dos setores e, às vezes, quando a direção toma conhecimento, tudo já foi resolvido. O colegiado foi uma mudança... envolve as pessoas. Se encontra soluções para os 'nós' 
nas relações interpessoais. O caminho é esse, a descentralização das decisões" (Assistente Social).

Esse novo modo de fazer gestão possibilita movimentos propositivos de mudanças, por meio de transformações criativas. Ao invés de se deixar envolver e acomodar-se com a realidade do cotidiano, pode resgatar-se a capacidade de ação dos sujeitos de perceber as organizações como estruturas vivas, que podem ser do modo como os usuários necessitam que sejam. Organizações vivas em que trabalhadores sejam incentivados a estar como um coletivo organizado, motivado e responsável.

A cogestão requer a tomada de decisões coletivas e um processo de discussão e negociação permanente, visando a uma recomposição com outros saberes, desejos e interesses. Diferentemente da autogestão, a cogestão pressupõe não haver poder nem dominação absolutos, mas constante relação com outros graus de poder e de dominação (CAMPOS, 1998).

As mudanças efetivadas na ambiência e na organização do trabalho foram vistas como disparadoras de uma nova forma de atenção e cuidado dispensado aos usuários.

"Já percebemos mudanças na chegada ao pronto-socorro. A implantação do ACCR reorganizou melhor a entrada do paciente e... existe o empenho para tentar melhorar cada vez mais... só que eu vejo que somos um hospital pioneiro nessa forma de gestão. Se a Secretaria de Saúde implantasse essa mesma forma em outros hospitais, a realidade seria diferente" (Técnico de Enfermagem).

"Hoje estamos trabalhando com uma lógica diferente, cada um trabalha para prestar melhor assistência ao usuário. E para isso é necessário esse envolvimento... todos comprometidos com aquele fazer... considerando a singularidade das pessoas que nos procuram" (Psicóloga).

Ressalta-se ainda a importância atribuída, pelos profissionais, aos espaços de capacitação criados: efetivando as rodas de conversa, fóruns dos trabalhadores e oficinas, constituídos por meio do processo de educação permanente.

"As rodas de conversa, os fóruns dos trabalhadores, espaço de capacitações geram novos conhecimentos e oportunidades. Uma mudança grande, um espaço aberto para todos os trabalhadores. Agora a gente está mais aberto e consciente" (Técnico de Nível Superior).

"Antes não tínhamos um projeto de educação permanente, tínhamos treinamentos pontuais. Hoje, temos um programa de educação permanente que está sendo aperfeiçoado a cada dia" (Técnico de Nível Superior/Gestão de Pessoas).

"A gente tem dentro da gestão de pessoas um núcleo de educação permanente, esse núcleo tem interagido com as unidades e os trabalhadores têm parado para discutir as suas necessidades. Agora 
mesmo estamos tendo uma atividade com os médicos do prontosocorro, tudo pensado e organizado por eles com apoio do núcleo. Se a gente comparar o que tínhamos há cinco anos e o que já foi feito nos últimos anos, é bem evidente a mudança" (Enfermeira).

A educação permanente em saúde pode ativar processos vivos de transformação, que questionam o naturalizado e permitem movimentos propositivos de mudança. A grande possibilidade de quebra da lógica predominante é sua desconstrução no espaço da micropolítica, no espaço da organização do trabalho e das práticas de saúde. Portanto, é imprescindível transformar a gestão e criar a possibilidade para que, no espaço coletivo, as pessoas descubram que têm o poder de mudar, que as angústias e conflitos possam ser trabalhados, apontando para outras direções e interpretações, outras práticas e outros compromissos sociais.

Nessa direção, a consolidação das unidades de produção no HGT vem concretizando e fortalecendo os espaços onde os trabalhadores discutem as rotinas, os protocolos, os conflitos e o sofrimento diante da doença e das dores da morte.

As possibilidades de inovação e mudança das concepções e práticas de saúde dentro das organizações dependem da ruptura com a alienação do trabalho, do resgate da possibilidade de produzir conhecimento a partir das práticas e da democratização da gestão dos processos de trabalho. Dessa forma, a Educação Permanente em Saúde é parte constitutiva da gestão democrática, ou seja, uma estratégia para a gestão de coletivos.

\section{A percepção sobre as dificuldades do processo}

\section{DIFICULDADE PARA EFETIVAÇÃO DA COGESTÃO}

\section{DESCRENÇA COM A COGESTÃO}

- Resistência a mudanças, por não acreditarem que a participação no processo da cogestão altere o atual contexto da instituição.

- Existência de uma cultura que se traduz no descrédito com o serviço público.

- Falta de credibilidade com a cogestão mostrando pouca ou nenhuma participação no processo; falta de compreensão da nova concepção de gestão.

- Exigem mudanças rápidas e imediatas, e por isso não acreditam no processo de cogestão.

- Confundem cogestão com liberdade, e ausência de regras. DESESTRUTURAÇÃO DO SISTEMA DE SAÚDE NO RN

- Descrevem a fragmentação da rede de saúde, que por sua vez interfere no cuidado integral e na resolutividade dos problemas de saúde.

- Entendem a fragmentação e a falta de resolutividade como um impacto negativo na cogestão.

- Percebem que a falta de condições de trabalho dificulta uma maior adesão à cogestão.

\section{DESVALORIZAÇÃO DO TRABALHADOR}

- Referem à desvalorização do trabalhador pela SESAP.

- Citam sobrecarga de trabalho e consequentemente o absenteísmo com comprometimento da qualidade de assistência.

- Falta de apoio institucional para admissão de novos profissionais comprometendo 
a cogestão do HGT.

- Falta de valorização dos trabalhadores que, no processo de trabalho, conseguiram se destacar por meio de efetivação de ações com qualidade. Reconhecem que o diálogo entre os gestores é, de certa forma, insuficiente.

Figura 04- Percepção sobre as dificuldades da cogestão.

Muitos elementos foram apontados como empecilhos (Figura 4), dificultando o processo de gestão participativa do HGT. Para facilitar tal compreensão essa categoria foi decomposta em três subcategorias: desestruturação da rede de saúde no $R N$; desvalorização do trabalhador por parte da instituição (SESAP); descrença com a cogestão.

Destaca-se que nessa categoria de análise, houve uma expressão significativa daqueles trabalhadores que não participaram efetivamente do processo de cogestão, entretanto, bastante relevantes para a análise em foco.

Sabe-se que os problemas estruturais enfrentados pelo Sistema Único de Saúde são muitos. Estes, vão desde a insuficiência de leitos até a falta de material e de pessoal, incidindo diretamente sobre a assistência ambulatorial e hospitalar e trazendo graves consequências para a população e para os trabalhadores de saúde. Dessa forma, alguns deles foram apontados como comprometedores do processo de gestão participativa: a falta de autonomia financeira das unidades assistenciais, as precárias condições de trabalho e o perfil profissional inadequado. Somam-se a isso a falta de apoio do governo, através da Secretaria Estadual de Saúde, ao processo instalado no HGT, que se diga, pioneiro na rede pública de saúde do estado. Entretanto, sob total responsabilidade dos técnicos que não se conformaram em deixar o HGT caminhar rumo ao declínio.

"Vemos como dificuldade a desestruturação do sistema de saúde no Rio Grande do Norte. Isso reflete nessa gestão porque a gente não consegue viabilizar as condições de trabalho necessárias para os trabalhadores desenvolverem as ações de saúde" (Técnico terceirizado).

"Há um isolamento desse processo de gestão participativa aqui. Quando na verdade nós não somos uma ilha, mas fazemos parte de uma rede estadual de saúde que possui 23 hospitais. Mas, a gestão participativa é somente a gente que faz... É difícil, porque a gestão do nível central dá apoio ao Hospital, mas está bem distante da gestão participativa" (Médico).

A desvalorização do trabalho e do trabalhador, por meio de salários defasados, a ausência de planos de cargos e carreiras e a sobrecarga de trabalho, também são fatores que desestimulam os trabalhadores, prejudicando a constituição de equipes de referência nas unidades de produção do HGT, além de provocar aumento nos índices de adoecimento e de absenteísmo e, consequentemente, desmotivação e desinteresse em se implicar com a gestão participativa.

"Muitos, não se envolvem no processo. Infelizmente, há anos o trabalhador vem sentindo desvalorizado... então... a gente não acredita que vai mudar. E por não acreditar que vai mudar a gente 
não se empenha. É difícil participar das reuniões do colegiado" (Bioquímico).

"Muitos ainda não têm o conhecimento de gestão participativa, aí, acham que não adianta. Pelo fato de sempre ter acontecido tudo de cima para baixo... assusta ao participar, você se expõe, dando sua opinião... nossa cultura não é essa. É mais fácil dizer: não vou porque não adianta" (Maqueiro).

"As pessoas acham que não adianta... que não tem jeito, ou por comodismo ou porque são imediatistas. Nada muda de uma hora para outra. É preciso estimular mesmo para que os profissionais participem. Encontrar um meio de motivar os servidores. Quando eles estiverem participando... aí... não deixar cair" (Farmacêutico).

Um grande entrave referido no processo de cogestão no HGT diz respeito a pouca participação dos representantes do controle social no processo implantado. Há uma pequena inserção dos usuários nos espaços de debate e de reflexão sobre a implementação das propostas. Essa é uma demanda que exige muito esforço e apoio institucional para que de fato se concretize. Superar as barreiras para que seja garantida a participação dos usuários, é uma tarefa complexa e que necessita de apoio do controle social e abertura de todos os sujeitos que constroem e apoiam esse novo desenho no HGT.

A participação dos usuários no processo de cogestão ainda é pequena. Eles têm uma participação mais sistemática na Enfermaria de Pediatria, com participação em reuniões semanais. Nesse espaço ocorrem momentos lúdicos integrativos que fortalecem a relação entre a criança usuária e seu familiar acompanhante. Destacam-se, ainda, ações educativas de autocuidado envolvendo usuários do Ambulatório de Hanseníase.

Além disso, o Serviço de Assistência Especializada em HIV/AIDS realiza mensalmente encontros com usuários, representantes do Programa Estadual de DST/AIDS e Hepatites Virais, direção e profissionais das diversas categorias da unidade, objetivando a análise, discussão e elaboração conjunta de propostas que viabilizem melhorias na assistência prestada. Assim, o espaço denominado de Fórum dos usuários tem realizado, de forma sistemática, reuniões mensais com temas e questões pactuadas.

É sabido que a inclusão da rede afetiva e social dos usuários durante o seu trajeto nos estabelecimentos de saúde, além de direito de cidadania garantido em lei, é uma forte estratégia para ampliação da corresponsabilização destes, no processo do cuidado. É imprescindível a defesa dos interesses dos usuários nas organizações de saúde, cuja dinâmica de funcionamento, quando não acompanhada crítica e coletivamente, tende a dar vasão a processos e atitudes perversas que atentam contra a dignidade humana.

Observam-se avanços ao longo do trajeto da gestão participativa implantada no HGT, entretanto, as dificuldades se entrelaçam nessa teia: resistência ao novo modelo de atenção e gestão, por parte de alguns trabalhadores e gerentes; existência de conflitos interpessoais em algumas unidades funcionais; fragilidade no compromisso e responsabilização por parte de alguns servidores; estrutura física precária, déficit orçamentário ocasionado pelo subfinanciamento do Sistema de Saúde; déficit quantitativo de servidores e, como citado anteriormente, a pouca participação dos usuários no processo. 


\section{CONCLUSÕES}

Deflagrar e dar suporte para garantir a "gestão participativa" não é uma tarefa fácil, uma vez que, tendências contrárias às ideias de democratização, de corresponsabilização e de cuidado interdisciplinar, persistem como pontos de resistência frente às inovações institucionais. Nesse sentido, um dos desafios é criar estratégias que fomentem o compromisso e a corresponsabilização dos profissionais que ainda não estão envolvidos no processo. Observam-se diferenças tanto no perfil dos gerentes quanto no perfil dos trabalhadores envolvidos. Há trabalhadores em final de carreira, adoecidos, desmotivados, com dificuldades de se implicarem, bem como, há trabalhadores novatos, concursados, motivados, que acreditam nas mudanças e apresentam disposição e comprometimento, potencializando o pulsar da cogestão.

O incremento da Educação Permanente em Saúde dentro do HGT apresenta-se como estratégia essencial, devendo concretizar-se plenamente, e fazer parte da agenda da gestão se constituindo também como estratégia indispensável para a construção do SUS que queremos.

Analisa-se que apesar das barreiras apresentadas no processo da cogestão do HGT, a implantação da gestão participativa vem trazendo melhorias internas ao Hospital, repercutindo positivamente sobre a assistência prestada ao usuário, principalmente, nos últimos dois anos. Evidencia-se a percepção de uma nova relação de trabalho, com horizontalização do poder e dos processos decisórios. A percepção dos sujeitos acerca desse processo é, de modo geral, positiva, destacando-se a democratização das relações e a autonomia destes.

A gestão participativa vem concretizando um novo arranjo interno no Hospital, organizando os espaços da assistência ofertada aos usuários. Observa-se que grande parte das facilitações ocorreu nas unidades funcionais, onde cada uma delas comporta características e sujeitos singulares, denotando níveis de organização diferenciados.

Por fim, entende-se que a implementação do novo desenho de Gestão Participativa deve ser uma construção contínua, fazendo-se necessário estar atento aos constantes desafios experimentados no campo da gestão e da atenção hospitalar para que possa ser possível diminuir a distância entre intenção e gesto.

\section{REFERÊNCIAS BIBLIOGRÁFICAS}

1. BARDIN, L. Análise de conteúdo. Lisboa: Edições 70, 2010, 281p.

2. BARROS, R. B.; BARROS, M. E. B. Da dor ao prazer no trabalho. In: SANTOS FILHO, S. B.; BARROS, M. E. B. (Orgs.) Trabalhador da saúde, muito prazer! Protagonismo dos trabalhadores na gestão do trabalho em saúde. São Paulo: Catavento, 2007, p. 63-71.

3. BENEVIDES, R; PASSOS, E. Humanização na saúde: um novo modismo? Interface: Comunicação, Saúde e Educação, São Paulo, v. 9, n. 17, p. 389-406, 2005. 
4. BOURDIEU P. O Poder Simbólico. Rio de Janeiro: Editora Bertrand Russel; 1998.

5. BOURDIEU P. Esboço de uma teoria da prática. Oiras: Celta Editora; 2002.

6. BRASIL. Ministério da Saúde. Secretaria de Atenção à Saúde. Departamento de Ações Programáticas e Estratégicas. Atenção hospitalar. Brasília: Ministério da saúde, 2012. (Cadernos HumanizaSUS, v. 3).

7. BRASIL. Ministério da Saúde. Secretaria de Atenção à Saúde. Política Nacional de Humanização. Formação e intervenção. Brasília: Ministério da Saúde, 2010 (Série B. Textos Básicos de Saúde) (Cadernos HumanizaSUS ; v. 1).

8. BRASIL. Ministério da Saúde. Secretaria de Atenção à Saúde. Política Nacional de Humanização da Atenção e Gestão do SUS. Acolhimento e classificação de risco nos serviços de urgência. Brasília: Ministério da Saúde, 2009a.

9. BRASIL. Ministério da Saúde. Secretaria de Atenção à Saúde. Política Nacional de Humanização da Atenção e Gestão do SUS. Acolhimento e classificação de risco nos serviços de urgência. Brasília: Ministério da Saúde, 2009b.

10. CAMPOS, G. W. S. Anti-Taylor: sobre a invenção de um método para co-governar instituições de saúde produzindo liberdade e compromisso. Cad. Saúde Pública, v. v. 14, n. 4, p. 863-870, 1998.

11. CAMARGO BV. ALCESTE: um programa informático de análise quantitativa de dados textuais. Florianópolis: Universidade Federal de Santa Catarina; 1998.

12. CECÍlLIO. L. C. O. Modelos tecnoassistenciais em saúde: da pirâmide ao círculo, uma possibilidade a ser explorada. Cadernos de Saúde Pública, Rio de Janeiro. v. 13, n. 3, jul./set. 1997, p. 469-478.

13. CECÍlIO, L. C. O. Mudar modelos de gestão para mudar o hospital: cadeia de apostas e engenharia de consensos. Espaço para a Saúde, v. 1, n. 2, p. 4-26, 2000.

14. DENZIN NK. The Research Act: A Theoretical Introduction to Sociological Methods. Chicago: Aldine Publishing Company; 1973.

15. FLICK, U. Desenho da pesquisa qualitativa. Porto Alegre: Artmed, 2009.

16. FREIRE, M. T. C. et al. O processo de gestão participativa no Hospital Giselda Trigueiro: sentimento coletivo de trabalho pelo SUS. In: BRASIL. Ministério da Saúde. Secretaria de Atenção à Saúde. Política Nacional de Humanização. Atenção Hospitalar. Brasília: Ministério da Saúde, 2011. (Cadernos HumanizaSUS, v. 3).

17. MATHIAS, M. Um balanço da Política Nacional de Educação Permanente em Saúde. RET-SUS, ano 5, n. 39, p.12-17, 2010.

18. OLIVEIRA, G. N. O apoio institucional aos processos de democratização das relações de trabalho na perspectiva da humanização. Revista Tempus actas de saúde coletiva, v. 6, n. 2, p. 223-235, 2012.

19. PASCHE, D. F. Política Nacional de Humanização como aposta na produção coletiva de mudanças nos modos de gerir e cuidar. Interface: Comunicação, Saúde e Educação, v. 13, p. 701-708, 2009. Suplemento 1.

20. SILVA, M. G. A.; FÉ, M. V. S; MARTINS, M. M. C. O hospital que temos e o hospital que queremos: construindo o processo de gestão participativa no Hospital Giselda Trigueiro. Monografia (Especialização em Gestão do Hospital Público) Universidade Federal do Rio Grande do Norte, Natal, 2009. 
